\title{
Analysis of genetic polymorphisms of brain-derived neurotrophic factor and methylenetetrahydrofolate reductase in depressed patients in a Slovak (Caucasian) population
}

\author{
Andrea Evinova ${ }^{1}$, Eva Babusikova ${ }^{1}$, Stanislav Straka ${ }^{1}$, Igor Ondrejka ${ }^{2}$ and Jan Lehotsky ${ }^{1}$ \\ 1 Department of Medical Biochemistry, Jessenius Faculty of Medicine in Martin, Comenius University Bratislava, Slovak \\ Republic \\ 2 Clinic of Psychiatry, Jessenius Faculty of Medicine in Martin, Comenius University Bratislava, Slovak Republic
}

\begin{abstract}
Major depressive disorder (MDD) is a complex neuropsychiatric disorder where both gene-gene and gene-environment interactions play an important role, but the clues are still not fully understood. One carbon metabolism in the CNS plays a critical role in the synthesis and release of neurotransmitters which are relevant to depressive disorder. We studied genetic polymorphisms of the brain derived neurotrophic factor (BDNF) and the methylenetetrahydrofolate reductase (MTHFR) in association with major depressive disorder. We genotyped the BDNF G196A, the MTHFR C677T, and A1298C polymorphisms in 134 patients diagnosed with major depression and 143 control subjects in Slovak (Caucasian) cohort of patients and probands. We found no significant association of either the BDNF G196A or MTHFR C677T polymorphisms with major depressive disorder neither in female nor male group of patients. However, the MTHFR A1298C genotype distribution was $36.6 \%$ (for AA genotype), 48.5\% (AC) and 14.9\% (CC) for the depressed patients, and $48.9 \%$ (AA), $42.7 \%$ (AC) and $8.4 \%$ (CC), respectively, for the control subjects. Patients with MDD had a higher prevalence of the CC genotype $(\mathrm{OR}=2.38 ; 95 \% \mathrm{CI}=1.07-5.32 ; p=0.032)$ and the $\mathrm{AC}+\mathrm{CC}$ genotype $(\mathrm{OR}=1.67 ; 95 \% \mathrm{CI}=1.03-2.69 ; p=0.037)$ in comparison with the control subjects. This study shows that CC genotype of the MTHFR A1298C is associated with higher risk of MDD in Slovak population.
\end{abstract}

Key words: Depression - Polymorphism - Methylenetetrahydrofolate reductase - Brain-derived neurotrophic factor

\section{Introduction}

Many psychiatric disorders including major depressive disorder (MDD) are characterized by structural alterations in specific limbic regions. These changes result from atrophy and loss of neurons and glia (Duman 2004). MDD is a complex neuropsychiatric disorder where both gene-gene and gene-environment interactions play an important role, but still is not fully understood.

Correspondence to: Jan Lehotsky, Department of Medical Biochemistry, Jessenius Faculty of Medicine in Martin, Comenius University Bratislava, Mala Hora 4, 03601 Martin, Slovak Republic

E-mail: lehotsky@jfmed.uniba.sk
Brain-derived neurotrophic factor (BDNF) is $27-\mathrm{kDa}$ polypeptide, belongs to the family of neurotrophin growth factors which are essential in neuronal development, survival and plasticity. BDNF is synthetized as a precursor protein (proBDNF); mature BDNF is formed when proBDNF is proteolytically cleaved by extracellular proteases (Lessmann et al. 2003). The human BDNF gene is located on chromosome 11p13. Egan et al. (2003) have identified G196A single nucleotide polymorphism in the gene encoded BDNF. The $B D N F$ G196A polymorphism results in a valine (Val) to a methionine (Met) change at position 66 (Val66Met). This polymorphism markedly alters the intracellular trafficking and packaging of proBDNF. Brain-derived neurotrophic factor widely influences hippocampal neurogenesis and plays an important role in the pathogenesis of the depression (Altar 1999; Duman 2004). In humans, the Met allele has 
been associated with poorer episodic memory, abnormal hippocampal activation, and lower hippocampal concentration of $\mathrm{N}$-acetylaspartate (Egan et al. 2003). Geller et al. (2004) found that the Val allele was preferentially identified mainly in Caucasian adult probands with bipolar disorder. Lower plasma concentrations of BDNF in depressive patients were observed by Karege et al. (2002). A decreased content of BDNF was documented in the brain cortex and hippocampus in post mortem studies of depressive patients (Dwivedi et al. 2003). But, the association of the BDNF gene polymorphism with depression is still ambiguous.

In addition, still is very little known about the metabolic aspects of the disease, such as role of the one carbon metabolism in the pathogenesis of major depressive disorder. Methylenetetrahydrofolate reductase (MTHFR) catalyses the conversion of 5,10-methylenetetrahydrofolate to 5methyltetrahydrofolate. Homocysteine or its metabolites may have an excitotoxic effect to neurons and may inhibit methylation processes in the central nervous system (Bottiglieri et al. 1994). Gene for MTHFR is located on chromosome 1p36.3. A common mutation of the MTHFR gene is the C677T change, which converts alanine to valine, results in a thermo-labile enzyme with decreased activity (Ueland et al. 2001). Patients with homozygous 677TT genotype had significantly elevated plasma concentration of homocysteine levels, and decreased serum folate concentration. The heterozygote and homozygous variant of the MTHFR C677T were shown to have $65 \%$ and $30 \%$ of the enzyme activity (Rozen 1996). Another functional polymorphic site was identified in exon 7 by van der Put et al. (1998). An A1298C mutation results in a glutamate to alanine change. This mutation also leads to decreased MTHFR activity, which was more pronounced in the homozygous than heterozygous state (Lievers et al. 2001). Both the C677T and A1298C single nucleotide polymorphisms (SNPs) in the MTHFR gene decrease the activity of the enzyme, leading to hyperhomocysteinemia, particularly in folate-deficient states, however this type of study is still missing with Slovak (Caucasian) cohort of patients.

In the present study, we examined the associations of the brain derived neurotrophic factor G196A polymorphism, methylenetetrahydrofolate reductase C677T, and A1298C genetic polymorphisms in patients with MDD. Although few studies confirmed the association of MTHFR polymorphisms with MDD, studied groups had often less than one hundred patients (van den Put et al. 1998; Reif et al. 2005). Thus the contribution of these polymorphisms to MDD is still questioned. The aim of our study performed on 134 MDD selected Slovak cohort of patients was to examine the possible linkage of these three different polymorphisms with MDD. In addition, we report for the first time a double association analysis on MTHFR polymorphisms in connection with MDD in Slovak population.

\section{Material and Methods}

The patient group was comprised of 134 inpatients with average age $48 \pm 13.9$ (from 21 to 81 years, median 49 ) of which $60.7 \%$ were women with average age $49 \pm 14.6$ (from 21 to 81 years, median 49 ) and $39.7 \%$ were men with average age $47 \pm 12.8$ (from 22 to 59 years, median 48 ) suffered from major depressive disorder with single episode or recurrent, and without other psychiatric comorbidities (as anxiety disorders, alcohol and drug addictions). Patients with bipolar disorder were excluded from the study. Diagnosis was confirmed by two independent psychiatrists at the Psychiatric Clinic of University Hospital Martin (Slovakia) according to DSM-IV-TR (Diagnostic and Statistical Manual of Mental Disorders, Fourth Edition, Text Revision) and ICD-10 (The ICD-10 Classification of Mental and Behavioral Disorders) classifications. The core symptoms of depression are depressed mood, and loss of interest or pleasure. At least one of these symptoms (depressed mood or loss of interest or pleasure) is present for at least two weeks according to DSM-IV-TR classification. For the complexity of diagnosis a rating scale (MADRS score) was used too. Patients with primary depression (moderate, severe or psychotic form) were hospitalized at the Psychiatric Clinic of University Hospital Martin (Slovakia) after the failure of ambulance treatment. The patients were hospitalized for an acute treatment from four to seven weeks. After that they were released from hospital to the daily hospital when the MADRS score dropped at least about $50 \%$.

The control group consisted of 143 volunteers blood donors with average age $37 \pm 11.3$ (from 19 to 63 years, median 36 ) of which $60.1 \%$ were men (average age of $37 \pm 11.3$ from 19 to 57 years, median 37 ) and $39.9 \%$ were women (average age of $36 \pm 12.1$, from 20 to 63 years, median 35), as they claimed to be feeling well and intended to donate blood. All subjects gave their informed consent prior to participate in this study. The study was approved by the Bioethics Committee of Jessenius Faculty of Medicine in Martin, Slovakia.

Genomic DNA was extracted from peripheral blood leukocytes according to commercial procedure (Wizard Genomic DNA purification kit, Promega). Analyzed polymorphic variants of the BDNF (rs6265) and MTHFR (rs1801133, rs1801131) were determined using the PCR-RFLP method. The BDNF G196A SNP was genotyped by PCR according to the protocol originally described by Egan et al. (2003). PCR was performed in a final volume of $25 \mu \mathrm{l}$ with $40 \mathrm{ng}$ of DNA, $25 \mathrm{nmol} / \mathrm{l}$ primers and $12.5 \mu$ Readymix REDTaq polymerase (Sigma-Aldrich). PCR products were digested with Fast digest restriction enzyme PmlI (Fermentas) at $37^{\circ} \mathrm{C}$ $5 \mathrm{~min}$. DNA fragments were separated by electrophoresis on $2 \%$ agarose gel and visualized by UV illuminator. Three possible genotypes were found: GG 124bp, 180bp; GA 124bp, 180bp, 304bp; AA 304bp. 
The MTHFR C677T SNP was genotyped by PCR according to the protocol originally described by Frosst et al. (1995). PCR product was digested with Fast digest restriction enzyme HinfI (Fermentas) at $37^{\circ} \mathrm{C} 5 \mathrm{~min}$. The $\mathrm{C}$ allele corresponded to an undigested 206bp fragment, while the T allele corresponded to $160 \mathrm{bp}$ and $46 \mathrm{bp}$ digested fragments. The MTHFR A1298C SNP was genotyped by PCR according to the protocol originally described by van der Put et al. (1998). Glutamate allele of the PCR product was digested at $37^{\circ} \mathrm{C}$ using Fast digest restriction enzyme $\mathrm{MboII}$ (Fermentas) and separated on $2 \%$ agarose gel and genotyped according to the length of the digested PCR products. Homozygous genotypes were identified by the presence of a single 204bp band (CC) or by bands of 150bp and 54bp (AA).

The $\chi^{2}$ method was used to test frequencies of alleles and genotypes among depressed patients and controls. The odds ratios (OR), which estimate relative risk, with $95 \%$ confidence intervals (CI) were calculated to assign the strengths of association of the genotypes with MDD. For the double association analysis the $\chi^{2}$ method was used, too. Differences resulting in a $p$ value of less or equal to 0.05 were considered statistically significant. Distribution of genotypes was tested for deviation from Hardy-Weinberg equilibrium.

\section{Results}

The distribution of the BDNF G198A, MTHFR C677T, and MTHFR A1298C allele and genotype frequencies among the group of control subjects and cohort of the depressed patients from Slovak (Caucasian) population are shown in Tables 1 and 2. As a measure for quality group, distribution of genotypes in three SNPs was analyzed and has found to fit in Hardy-Weinberg equilibrium (results not shown). To assess the variant allele positivity, we analyzed heterozygous and polymorphic genotypes together.

As shown in the Table 1, we have analyzed the association of the BDNF Val/Met (G196A) polymorphism with the incidence of MDD. We genotyped 134 patients with confirmed MDD, 75.4\% of which had the GG genotype, $20.9 \%$ had the GA genotype, and $3.7 \%$ had the AA genotype. Genotype frequencies in the control Slovak probands were as follows: $69.9 \%$ for the GG genotype, $26.6 \%$ for the GA genotype and 3.5\% for the AA genotype. As seen from the Table 1, the GG genotype and G allele was present more frequently in patients with MDD than in healthy Slovak volunteers. We have observed no statistically significant differences in the genotype or allele frequencies of $B D N F$ G196A polymorphism in the cohort of the MDD patients and control subjects neither for the $G$ allele nor for the A allele of BDNF.

However, the genotype distribution according to gender showed slightly different results, but they were not statistically significant. In men, we observed 1.15-fold increased risk $(95 \% \mathrm{CI}=0.62-2.16)$ for the A allele in depressed group (19.6\%) compared with controls (17.4\%). On the contrary, in women we found lowered risk $(\mathrm{OR}=0.65,95 \% \mathrm{CI}=0.32$ - 1.31) for the A allele among the depressed group (10.8\%) and controls (15.8\%).

The genotype and allele frequency distribution of MTHFR C677T polymorphism in Slovak MDD patients and control subjects is shown in Table 2. We have analyzed cohort of 134 depressed patients for the MTHFR C677T polymorphism. As can be seen from results, the frequency of the CC genotype in MDD group was $52.2 \%$, the heterozygous CT genotype was $40.3 \%$, and the TT genotype was $7.5 \%$. In healthy volunteers, the distribution of genotypes was found as follows: $40.5 \%$ for the CC genotype, $51.1 \%$ for the CT genotype and $8.4 \%$ for the TT genotype. We did not observe a significant difference between the heterozygous CT (OR $=0.61,95 \%$ $\mathrm{CI}=0.37-1.01, p=0.052)$ and variant $\mathrm{TT}(\mathrm{OR}=0.69$, $95 \% \mathrm{CI}=0.28-1.71, p=0.42$ ) genotypes in comparison to the $\mathrm{CC}$ genotype in this group of probands. In addition, there were not statistically significant differences in the incidence of genotypes and alleles. However, the values for the heterozygous CT genotype in comparison to the wild CC genotype as a potentially protective genotype to MDD were boundary $(p=0.052)$.

Table 1. Genotype frequencies of the BDNF G196A polymorphism in the cohort of patients with major depressive disorder (MDD) and in control subjects

\begin{tabular}{lccccc}
\hline $\begin{array}{l}\text { BDNF G196A } \\
\text { genotype }\end{array}$ & $\begin{array}{c}\text { Controls } \\
(n=143)\end{array}$ & $\begin{array}{c}\text { Patients } \\
(n=134)\end{array}$ & OR $(95 \%$ CI $)$ & $p$ & $\chi^{2}$ \\
\hline GG & 100 & 101 & 1.00 & & \\
GA/GG & 38 & 28 & $0.73(0.42-1.28)$ & 0.270 & 1.22 \\
AA/GG & 5 & 5 & $0.99(0.28-3.53)$ & 0.988 & 0.00 \\
GA+AA/GG & 43 & 33 & $0.76(0.45-1.29)$ & 0.310 & 1.03 \\
Allele G & 238 & 230 & $1.22(0.77-1.94)$ & 0.398 & 0.72 \\
Allele A & 48 & 38 & $0.82(0.52-1.30)$ & 0.398 & 0.72 \\
\hline
\end{tabular}

$n$, number of probands; OR, odd ratio; CI, confidence interval. 
Table 2. Genotype frequencies of the MTHFR C677T and A1298C polymorphisms in the cohort of patients with major depressive disorder (MDD) and in control subjects

\begin{tabular}{|c|c|c|c|c|c|}
\hline & $\begin{array}{l}\text { Controls } \\
(n=143)\end{array}$ & $\begin{array}{l}\text { Patients } \\
(n=134)\end{array}$ & $\begin{array}{c}\text { OR } \\
(95 \% \text { CI })\end{array}$ & $p$ & $\chi^{2}$ \\
\hline \multicolumn{6}{|c|}{ MTHFR C677T genotype } \\
\hline $\mathrm{CC}$ & 58 & 70 & 1.00 & & \\
\hline CT/CC & 73 & 54 & $0.61(0.37-1.00)$ & 0.052 & 3.78 \\
\hline TT/CC & 12 & 10 & $0.69(0.28-1.71)$ & 0.423 & 0.64 \\
\hline $\mathrm{CT}+\mathrm{TT} / \mathrm{CC}$ & 85 & 64 & $0.62(0.39-1.00)$ & 0.051 & 3.80 \\
\hline Allele C & 189 & 194 & $1.35(0.94-1.93)$ & 0.108 & 2.58 \\
\hline Allele T & 97 & 74 & $0.74(0.52-1.07)$ & 0.108 & 2.58 \\
\hline \multicolumn{6}{|c|}{ MTHFR A1298C genotype } \\
\hline $\mathrm{AA}$ & 70 & 49 & 1.00 & & \\
\hline $\mathrm{AC} / \mathrm{AA}$ & 61 & 65 & $1.52(0.92-2.52)$ & 0.106 & 2.67 \\
\hline CC/AA & 12 & 20 & $2.38(1.07-5.32)^{\star}$ & $0.032^{*}$ & 4.62 \\
\hline $\mathrm{AC}+\mathrm{CC} / \mathrm{AA}$ & 73 & 84 & $1.66(1.03-2.69) *$ & $0.037^{\star}$ & 4.33 \\
\hline Allele A & 201 & 163 & $0.66(0.46-0.93)$ & 0.019 & 5.49 \\
\hline Allele C & 85 & 105 & $1.52(1.07-2.17)^{\star}$ & $0.019^{*}$ & 5.49 \\
\hline
\end{tabular}

${ }^{*}$ statistically significant results $(p<0.05)$. For abbreviations, see Table 1.

Consequently, when we analyzed genotype distribution according to gender, the distribution of genotypes was similar as it is shown in the Table 2. We did not detect statistically significant association of heterozygous CT genotype as a protective genotype to MDD neither for men nor for women $(p>0.05)$.

Unlike no association of MTHFR C677T polymorphism with MDD, the analysis of the same patients for another MTHFR polymorphism: MTHFR Glu/Ala (A1298C) showed statistically significant association with MDD. Distribution of genotypes in depressed group of patients was as follows: $36.6 \%$ for the AA genotype, $48.5 \%$ for the AC genotype, and $14.9 \%$ for the CC genotype. In control Slovak subjects we observed the following distribution of genotypes: $48.9 \%$ for the AA genotype, $42.7 \%$ for the AC genotype, and $8.4 \%$ for the CC genotype. The genotype and allele frequency distribution of MTHFR A1298C polymorphism in patients and control subjects is shown in Table 2. Interestingly, we found out a 2.38-fold increased risk of MDD incidence in individuals with the AA and CC genotype (OR $=2.38 ; 95 \%$ $\mathrm{CI}=1.07-5.32 ; p=0.032$ ). The result was also statistically significant when we compared the AC and CC genotype against the AA genotype, but the $\mathrm{OR}$ was lower $(\mathrm{OR}=1.66$; $95 \% \mathrm{CI}=1.03-2.69 ; p=0.038$ ). Allelic frequencies in depressed patients were $60.8 \%$ for the A allele and $39.2 \%$ for the risk $\mathrm{C}$ allele in comparison with healthy volunteers $70.3 \%$ for the A allele and $29.7 \%$ for the $\mathrm{C}$ allele. We have also observed a statistically significant association of the $\mathrm{C}$ allele with the increased risk of $\mathrm{MDD}(\mathrm{OR}=1.52 ; 95 \% \mathrm{CI}=1.07-2.17 ; p=$ $0.019)$. Genotype distribution according to gender showed similar tendency as the results for whole group. In men, we found statistically significant association of the risk CC genotype carriers $(\mathrm{OR}=3.1,95 \% \mathrm{CI}=1.01-9.6, p=0.042)$ compared to AA genotype carriers among the depressed group (17.7\%) and controls (7.4\%).

In women, we observed higher frequency of the risk CC genotype $(\mathrm{OR}=1.60,95 \% \mathrm{CI}=0.81-2.38)$ and the $\mathrm{C}$ allele $(\mathrm{OR}=1.38,95 \% \mathrm{CI}=0.48-5.3)$ in depressed group $(12.5 \%)$ compared to controls (10.4\%), but the difference was not statistically significant.

In addition, we also tried to uncover whether combination of two polymorphic sites in the MTHFR gene is associated with the incidence of MDD in Slovak population. We performed $\chi^{2}$ method to test frequency of coexistence of genotypes (CC, CT, TT) and (AA, AC, CC), to verify whether exists characteristic combination of the C677T and A1298C genotypes in patients suffering from MDD compared to healthy individuals. We have observed that the TT C677T and the AC A1298C genotypes are considerably associated with the higher risk of major depression disorder in Slovak population. Likewise, the OR analysis showed that persons with such a genotype combination are more than five times prone to develop depression than persons with other genotype combinations. However, detailed analysis showed that the result was not statistically significant (Table 3 ).

\section{Discussion}

Many studies proved, that one carbon metabolism in brain has a critical effect on intracellular pathways and neural function, including gene regulation, neurotransmitter 
Table 3. Double association analysis of the MTHFR C677T and A1298C polymorphisms in the cohort of patients with major depressive disorder (MDD) and in control subjects

\begin{tabular}{ccccccc}
\hline $\begin{array}{c}\text { MTHFR C677T } \\
\text { genotype }\end{array}$ & $\begin{array}{c}\text { MTHFR A1298 } \\
\text { genotype }\end{array}$ & $\begin{array}{c}\text { Controls } \\
(n=143)\end{array}$ & $\begin{array}{c}\text { Patients } \\
(n=134)\end{array}$ & $\begin{array}{c}\text { OR } \\
(95 \% \text { CI })\end{array}$ & $p$ & $\chi^{2}$ \\
\hline CC & AA & 18 & 17 & $1.02(0.50-2.07)$ & 0.550 & 0.00 \\
CC & AC & 27 & 33 & $1.40(0.79-2.49)$ & 0.155 & 1.35 \\
CC & CC & 11 & 18 & $1.86(0.85-4.11)$ & 0.086 & 2.43 \\
CT & AA & 40 & 27 & $0.65(0.37-1.14)$ & 0.084 & 2.31 \\
CT & AC & 33 & 26 & $0.80(0.45-1.43)$ & 0.275 & 0.56 \\
CT & CC & 0 & 1 & - & - & - \\
TT & AA & 12 & 5 & $0.45(0.15-1.32)$ & 0.107 & 2.61 \\
TT & AC & 1 & 5 & $5.50(0.63-47.74)$ & 0.092 & - \\
TT & CC & 0 & 0 & - & - & - \\
\hline
\end{tabular}

For abbreviations, see Table 1.

synthesis and synaptic function. Imbalances in one carbon metabolism therefore initiate complex cascades which appear to be related to a variety of neuropsychiatric disorders, such as chronic fatigue, depression, schizophrenia, psychosis and dementia (Coppen et al. 2000; Saetre et al. 2011; Suchanek et al. 2011).

Several authors reported positive association of BDNF polymorphism with affective disorders (Sen et al. 2003, 2008; Chen et al. 2006; Kaufman et al. 2006), but the results are inconsistent. Sen et al. (2003) published that allele A of $B D N F$ is associated with lower neuroticism in the common population, while Chen et al. (2006) observed in mouse models that with exprimed allele A number and length of apical dendrites in hippocampus and prefrontal cortex was lowered. BDNF G196A polymorphism was reported to be associated with bipolar disorder by Egan et al. (2003). Most of studies did not confirm the association of the BDNF gene polymorphism with MDD (Schumacher et al. 2005; Green et al. 2006; Kunugi et al. 2004). Similarly to the study of Schumacher et al. (2005) which examined 465 subjects with major depression also Surtees et al. (2007) did not find significant association of MDD with BDNF G196A polymorphism in 1214 subjects with a history of major depression. Suchanek et al. (2011) found GG genotype was more frequent in patients with recurrent major depressive disorder in studied cohort of Polish patients compared to the control group. In Slovak population with MDD, we did not observe a statistically significant association between $B D N F$ G/A polymorphism and MDD. The frequency of the combined variant AA and heterozygous GA genotypes and the wild type GG genotype was not significantly different in our cohort of depressed patients and control probands. Likewise, genotype and allelic distribution between men and women did not show statistically significant results, too. Thus, our study did not prove any association of BDNF G196A polymorphism with $\mathrm{MDD}$, and it is not likely that there is a direct relationship between the BDNF G196A polymorphism and vulnerability to major depressive disorder.

The association for the polymorphisms of the second studied gene, the MTHFR C677T with MDD, was first reported in 1998 by Arinami et al. on the group of Japanese subjects. Authors found that depressed patients have significantly higher prevalence of TT genotype; however, results can be questioned because studied group of patients comprised only 32 patients. Larger study including 71 patients was also accomplished on Japanese population with unipolar depression. In line of previous, this study did not prove any association between MTHFR polymorphisms and unipolar depression, too (Kunugi et al. 1998).

Bjelland et al. (2003) examined the association between folate, total homocysteine, vitamin B12, and the MTHFR C677T polymorphism and anxiety and depression in a large population-based study. Hyperhomocysteinemia and the TT genotype were significantly related to depression without comorbid anxiety disorder (Bjelland et al. 2003). They concluded that the results provided evidence for impaired 1-carbon metabolism in depression. The largest European women study on MTHFR polymorphism was realized in 2006 by Lewis et al. in the British Women's Heart and Health study. The study have included 545 women and found an evidence of an increased risk of depression in MTHFR TT polymorphic individuals compared with CC individuals with the $\mathrm{OR}=1.35,95 \% \mathrm{CI}=1.1-1.8$ (Lewis et al. 2006).

Later meta-analyses of genetic studies associated with major depressive disorder (Gilbody et al. 2007; Lewis et al. 2006; Zintzaras 2006; Lopez-Leon et al. 2008; Gaysina et al. 2008; Peerbooms et al. 2011) also reported the MTHFR $677 \mathrm{~T}(\mathrm{OR}=1.20)$ polymorphism as one of the six positively associated polymorphisms with MDD.

Recently, several case-control studies have analyzed cohorts of patient with the European origin, diagnosed with unipolar depression. All patients were based on DSM-IV 
or ICD 10 criteria, which have also been used in our study. Gaysina et al. (2008) published a powerful study in the British population which included 1222 depressed patients and 835 control subjects. The study was not decisive and authors found no linkage between the C677T polymorphism and major depression in British Caucasians ( $\mathrm{OR}=1.05)$. Results suggest for more equivocal role of the MTHFR C677T polymorphism in conferring susceptibility to recurrent unipolar depression. Later studies on Caucasian population showed also various results (Hernandez et al. 2009; Huang et al. 2010). While Huang et al. (2010) in the group of 178 patients did not find any positive association of the MTHFR C677T with unipolar depression, Hernandez et al. (2009) in a smaller cohort (21 patients) found significant statistical association of MTHFR and depression. Recent meta-analysis published by Peerbooms et al. (2011) have examined the association between MTHFR and multiple psychiatric disorders (such as schizophrenia, bipolar disorder, and depression together) using a cross-disorder design, not separately for particular disorders and found no decisive results. However, till now, no study was done in the Slovak population of depressed patients in association with MTHFR C677T polymorphism. Present paper is the first to prove that in Slovak population does not exist higher prevalence of the risk CT or TT genotypes of the MTHFR C677T polymorphism among the control and depressed group. Likewise, genotype distribution in men and women showed similar trend and we found no statistically significant differences. Thus, we can conclude that results of our study fits well with two other meta-analyses performed on Caucasian cohort of depressed patients (Zintzaras 2006, Gaysina et al. 2008).

Only one genetic study which shows the MTHFR A1298C polymorphism in connection with MDD was reported till now (Reif et al. (2005). Authors have reported for a positive association with MTHFR A1298C and MDD in Caucasians and found an odds ratio $3.25,95 \% \mathrm{CI}=1.19-8.88$, when $\mathrm{CC}$ variants were compared with the AA homozygote wild type genotype. In accordance with this study, we found a statistically significant association of the AC + CC and, the CC genotype and the C allele of the MTHFR A1298C polymorphism with MDD in our Slovak cohort. Statistically significant increases were shown in those patients who were carriers of C1298C (14.9\% in patients compared with $8.4 \%$ in healthy volunteers), and those who were carriers of $\mathrm{C} 1298 \mathrm{C}$ and $\mathrm{A} 1298 \mathrm{C}$ (63.4\% in patients and $51.1 \%$ in healthy volunteers). In men we found statistically significant increased risk of depression for those who were CC carriers $(p<0.05)$, in women we observed higher frequency of the CC genotype in depressed group compared to controls, but not statistically significant.

This study also provides for the first time a double association analysis of the C677T and the A1298C MTHFR polymorphic sites in association with MDD. Combined heterozygous genotypes for both MTHFR mutations resulted in features similar to those observed in TT homozygotes for the C677T mutation (van der Put et al. 1998). Even though, we found a 5.5 times higher prevalence of the variant TT combination and the heterozygous AC genotype in MDD group of Slovak Caucasian patients, result was not statistically significant. Thus, the final prove of positive association with statistical significance should be approved by further study with larger group of patients.

Major depressive disorder is a complex neuropsychiatric disorder, with heritability up to $40 \%$, but pathophysiology is still not fully understood. Analysis of genes polymorphisms which could be involved in the etiopathology of MDD could thus lead to discovery of novel markers for identification of patients with higher risk of development of MDD. In addition, findings detecting particular combinations of polymorphisms of different genes may confer to the exploration of earlier onset and /or presence of the severe forms of MDD.

Limitation: The main limitation of this study is relatively small sample size.

Acknowledgement. This research was supported by UK-211/2011 grant, MZ-2007/55-UK-16 grant, and by project "Identification of novel markers in diagnostic panel of neurological diseases"code: 26220220114, co-financed from EU sources and European Regional Development Fund. A. E., E. B., S. S., I. O. and J. L. have no conflict of interest and no financial interest in the publication of this manuscript.

\section{References}

Altar C. A. (1999): Neurotrophins and depression. Trends Pharmacol. Sci. 20, 59-62 http://dx.doi.org/10.1016/S0165-6147(99)01309-7

Arinami T., Yamada N., Yamakawa-Kobayashi K., Hamaguchi H., Toru M. (1997): Methylenetetrahydrofolate reductase variant and schizophrenia/depression. Am. J. Med. Genet. 74, 526-528

http://dx.doi.org/10.1002/(SICI)1096-8628(19970919)74:5<526:: AID-AJMG14>3.0.CO;2-E

Bjelland I., Tell G. S., Vollset S. E., Refsum H., Ueland P. M. (2003): Folate, vitamin B12, homocysteine, and the MTHFR 677C-T polymorphism in anxiety and depression: the Hordaland Homocysteine Study. Arch. Gen. Psychiat. 60, 618-626 http://dx.doi.org/10.1001/archpsyc.60.6.618

Bottiglieri T., Hyland K., Reynolds E. H. (1994): The clinical potential of ademetionine (S adenosylmethionine) in neurological disorders. Drugs 48, 137-152 http://dx.doi.org/10.2165/00003495-199448020-00002

Coppen A., Bailey J. (2000): Enhancement of the antidepressant action of fluoxetine by folic acid: A randomised, placebo controlled trial. J. Affect. Disord. 60, 121-130 http://dx.doi.org/10.1016/S0165-0327(00)00153-1 
Chen Z. Y., Jing D., Bath K. G., Ieraci A., Khan T., Siao C. J., Herrera D. G., Toth M., Yang C., McEwen B. S., Hempstead B. L., Lee F. S. (2006): Genetic variant BDNF (Val66Met) polymorphism alters anxiety-related behavior. Science 314, 140-143 http://dx.doi.org/10.1126/science.1129663

Duman R. S. (2004): Depression: a case of neuronal life and death? Biol. Psychiatry 56, 140-145 http://dx.doi.org/10.1016/j.biopsych.2004.02.033

Dwivedi Y., Rizavi H. S., Conley R. R., Roberts R. C., Tamminga C. A., Pandey G. N. (2003): Altered gene expression of brainderived neurotrophic factor and receptor tyrosine kinase B in postmortem brain of suicide subjects. Arch. Gen. Psychiatry 60, 804-815 http://dx.doi.org/10.1001/archpsyc.60.8.804

Egan M. F., Kojima M., Callicott J. H., Goldberg T. E., Kolachana B. S., Bertolino A., Zaitsev E., Gold B., Goldman D., Dean M., Lu B., Weinberger D. R. (2003): The BDNF val66met polymorphism affects activity-dependent secretion of BDNF and human memory and hippocampal function. Cell 112, 257-269 http://dx.doi.org/10.1016/S0092-8674(03)00035-7

Frosst P., Blom H. J., Milos R., Goyette P., Sheppard C. A., Matthews R.G., Boers G. J., den Heijer M., Kluijtmans L. A., van den Heuvel L. P. (1995): A candidate genetic risk factor for vascular disease: a common mutation in methylenetetrahydrofolate reductase. Nature Genet. 10, 111-113 http://dx.doi.org/10.1038/ng0595-111

Gaysina D., Cohen S., Craddock N., Farmer A., Hoda F., Korszun A., Owen M. J., Craig I. W., McGuffin P. (2008): No Association With the 5,10-Methylenetetrahydrofolate Reductase Gene and Major Depressive Disorder: Results of the Depression Case Control (DeCC) Study and a Meta-Analysis. Am. J. Med. Genet. Part B 147B, 699-706 http://dx.doi.org/10.1002/ajmg.b.30665

Geller B., Badner J. A., Tillman R., Christian S. L., Bolhofner K., Cook E. H. Jr. (2004): Linkage disequilibrium of the brain-derived neurotrophic factor val66met polymorphism in children with pre pubertal and early adolescent bipolar disorder phenotype. Am. J. Psychiat. 161, 1698-1700 http://dx.doi.org/10.1176/appi.ajp.161.9.1698

Gilbody S., Lewis S., Lightfoot T. (2007): Methylenetetrahydrofolate Reductase (MTHFR) Genetic Polymorphisms and Psychiatric Disorders: A HuGE Review. Am. J. Epidemiol. 165, 1-13 http://dx.doi.org/10.1093/aje/kwj347

Green E. K., Raybould R., Macgregor S., Hyde S., Young A. H., O'Donovan M. C., Owen M. J., Kirov G., Jones L., Jones I., Craddock N. (2006): Genetic variation of brain-derived neurotrophic factor (BDNF) in bipolar disorder: Case-control study of over 3000 individuals from the UK. Br. J. Psychiatry 188, 21-25 http://dx.doi.org/10.1192/bjp.bp.105.009969

Hernandez-Sanchez M. D. C., Gomez-Reino Rodriguez I., Cuello Hormigo L. (2009): Research on C677T polymorphism of the metiltetrahidrofolareductasa (MTHFR) in hospitalized patients due to greater depression in Unit of Psychiatry of Orense. Anales de Psiquiatria 25, 53-63 (in Spanish)

Huang J., Perlis R. H., Lee P. H., Rush A. J., Fava M., Sachs G. S., Lieberman J., Hamilton S. P., Sullivan P., Sklar P., Purcell S., Smoller J. W. (2010): Crossdisorder genomewide analysis of schizophrenia, bipolar disorder, and depression. Am. J. Psychiatry $167,1254-1263$

http://dx.doi.org/10.1176/appi.ajp.2010.09091335

Jacques P. F., Bostom A. G., Williams R. R., Ellison R. C., Eckfeldt J. H., Rosenberg I. H., Selhub J., Rozen R. (1996): Relation between folate status, a common mutation in methylenetetrahydrofolatereductase, and plasma homocysteine concentrations. Circulation 93, 7-9 http://dx.doi.org/10.1161/01.CIR.93.1.7

Karege F., Perret G., Bondolfi G., Schwald M., Bertschy G., Aubry J. M. (2002). Decreased serum brain-derived neurotrophic factor levels in major depressed patients. Psychiatry Res. 109, 143-148 http://dx.doi.org/10.1016/S0165-1781(02)00005-7

Kaufman J., Yang B. Z., Douglas-Palumberi H., Grasso D., Lipschitz D., Houshyar S., Krystal J. H., Gelernter J. (2006): Brain-derived neurotrophic factor-5-HTTLPR gene interactions and environmental modifiers of depression in children. Biol. Psychiatry 59, 673-680

http://dx.doi.org/10.1016/j.biopsych.2005.10.026

Kunugi H., Iijima Y., Tatsumi M., Yoshida M., Hashimoto R., Kato T., Sakamoto K., Fukunaga T., Inada T., Suzuki T., Iwata N., Ozaki N., Yamada K., Yoshikawa T. (2004): No association between the Val66Met polymorphism of the brainderived neurotrophic factor gene and bipolar disorder in a Japanese population: A multicenter study. Biol. Psychiatry 56, 376-378 http://dx.doi.org/10.1016/j.biopsych.2004.06.017

Kunugi H., Fukuda R., Hattori M., Kato T., Tatsumi M., Sakai T., Hirose T., Nanko S. (1998): C677T polymorphism in methylenetetrahydrofolate reductase gene and psychoses. Mol. Psychiatry 3, 435-437

http://dx.doi.org/10.1038/sj.mp.4000390

Lessmann V., Gottmann K., Malcangio M. (2003): Neurotrophin secretion: current facts and future prospects. Prog. Neurobiol. 69, 341-374 http://dx.doi.org/10.1016/S0301-0082(03)00019-4

Lewis S. J., Lawlor D. A., Smith G. D., Araya R., Timpson N., Day I. N. M., Ebrahim S. (2006): The thermolabile variant of MTHFR is associated with depression in the British Women's Heart and Health Study and a meta-analysis. Mol. Psychiatry 11, 352-360 http://dx.doi.org/10.1038/sj.mp.4001790

Lievers K. J., Boers G. H., Verhoef P., den Heijer M., Kluijtmans L. A., van der Put N. M., Trijbels F. J., Blom H. J. (2001): A second common variant in the methylenetetrahydrofolate reductase (MTHFR) gene and its relationship to MTHFR enzyme activity, homocysteine, and cardiovascular disease risk. J. Mol. Med. 79, 522-528 http://dx.doi.org/10.1007/s001090100253

Lopez-Leon S., Janssens A. C. J. W., Gonzalez-Zuloeta Ladd A. M., Del-Favero J., Claes S. J., Oostra B. A., van Duijn C. M. (2008): Meta-analyses of genetic studies on major depressive disorder. Mol. Psychiatry 13, 772-785 http://dx.doi.org/10.1038/sj.mp.4002088

Peerbooms O. L. J., van Os J., Drukker M., Kenis G., Hoogveld L., de Hert M., Delespaul P., van Winkel R., Rutten B. P. (2011): Meta-analysis of MTHFR gene variants in schizophrenia, bipolar disorder and unipolar depressive disorder: Evidence 
for a common genetic vulnerability? Brain Behav. Immun. 25, $1530-1543$

http://dx.doi.org/10.1016/j.bbi.2010.12.006

Reif A., Pfuhlmann B., Lesch K. P. (2005): Homocysteinemia as well as methylenetetrahydrofolate reductase polymorphism are associated with affective psychoses. Prog. Neuropsychopharmacol. Biol. Psychiatry 29, 1162-1168 http://dx.doi.org/10.1016/j.pnpbp.2005.06.027

Rozen R. (1996): Molecular genetics of methylenetetrahydrofolate reductase deficiency. J. Inherit. Metab. Dis. 19, 589-594 http://dx.doi.org/10.1007/BF01799831

Saetre P., Vares M., Werge T., Andreassen O. A., Arinami T., Ishiguro H., Nanko S., Tan E. C., Han D. H., Roffman J. L., Muntjewerff J.W., Jagodzinski P. P., Kempisty B., Hauser J., Vilella E., Betcheva E., Nakamura Y., Regland B., Agartz I., Hall H., Terenius L., Jönsson E. G. (2011): Methylenetetrahydrofolate reductase (MTHFR) C677T and A1298C polymorphisms and age of onset in schizophrenia: a combined analysis of independent samples. Am. J. Med. Genet. Part B 156, 215-224 http://dx.doi.org/10.1002/ajmg.b.31160

Schumacher J., Jamra R. A., Becker T., Ohlraun S., Klopp N., Binder E. B., Schulze T.G., Deschner M., Schmäl C., Höfels S., Zobel A., Illig T., Propping P., Holsboer F., Rietschel M., Nöthen M. M., Cichon S. (2005): Evidence for a relationship between genetic variants at the brain derived neurotrophic factor (BDNF) locus and major depression. Biol. Psychiatry 58, 307-314 http://dx.doi.org/10.1016/j.biopsych.2005.04.006

Sen S., Nesse R. M., Stoltenberg S. F., Li S., Gleiberman L., Chakravarti A., Weder A. B., Burmeister M. (2003): A BDNF coding variant is associated with the NEO personality inventory domain neuroticism, a risk factor for depression. Neuropsychopharmacology 28, 397-401

http://dx.doi.org/10.1038/sj.npp.1300053
Sen S., Duman R., Sanacora G. (2008): Serum brain-derived neurotrophic factor, depression, and antidepressant medications: meta analyses and implications. Biol. Psychiatry 64, 527-532 http://dx.doi.org/10.1016/j.biopsych.2008.05.005

Suchanek R., Owczarek A., Kowalski J. (2011): Association study between BDNF C-281A polymorphism and paranoid schizophrenia in Polish population. J. Mol. Neurosci. 46, 217-222 http://dx.doi.org/10.1007/s12031-011-9582-7

Surtees P.G., Wainwright N. W., Willis-Owen S.A., Sandhu M. S., Luben R., Day N.E., Flint J. (2007): No association between the BDNF Val66Met polymorphism and mood status in a nonclinical community sample of 7389 older adults. J. Psychiatr. Res. 41, 404-409 http://dx.doi.org/10.1016/j.jpsychires.2006.01.004

Ueland P. M., Hustad S., Schneede J., Refsum H., Vollset S. E. (2001): Biological and clinical implications of the MTHFR C677T polymorphism. Trends Pharmacol. Sci. 22, 195-201 http://dx.doi.org/10.1016/S0165-6147(00)01675-8

Van der Put N. M. J., Gabreels F., Stevens E. M. B., Smeitink J. A. M., Trijbels F. J. M., Eskes T. K., van den Heuvel L. P., Blom H. J. (1998) A second mutation in the methylenetetrahydrofolate reductase gene: an additional risk factor for neural-tube defects? Am. J. Hum. Genet. 62, 1044-1051 http://dx.doi.org/10.1086/301825

Zintzaras E. (2006): C677T and A1298C methylenetetrahydrofolate reductase gene polymorphisms in schizophrenia, bipolar disorder and depression: A meta-analysis of genetic association studies. Psychiatr. Genet. 16, 105-115 http://dx.doi.org/10.1097/01.ypg.0000199444.77291.e2

Received: March 2, 2012

Final version accepted: August 8, 2012 